\title{
Modelo Transteórico para controle de peso: conhecimentos de saúde e nutrição antes e após intervenções em uma unidade de saúde da família de Palmas/TO
}

\author{
Killya de Paiva Santos, Alinne Aurélio Carneiro, Graziela Ramirez de Figueiredo, Gabriela de \\ Campos Mendes, Marília Marilourdes Mendes Lima, Renata Andrade de Medeiros Moreira
}

\begin{abstract}
Resumo
A educação alimentar e nutricional busca desenvolver práticas alimentares saudáveis pela mudança comportamental. Assim, o Modelo Transteórico (MT) ao classificar o indivíduo em estágios de comportamento alimentar, parece possibilitar intervenções com melhores resultados na adoção de modos de vida mais saudáveis. Avaliar conhecimentos sobre saúde e nutrição em pré e pós-testes de intervenções nutricionais com usuários com excesso de peso de uma Unidade de Saúde da Família (USF) de Palmas. Os 28 usuários com excesso de peso que foram classificados segundo MT de Sutton et al (2003) na primeira parte da pesquisa, participaram de oficinas de Educação Alimentar e Nutricional sobre os quatro comportamentos-alvo do modelo (óleos e gorduras; porções; frutas, legumes e verduras-FLV; e exercício físico). As oficinas ocorreram entre agosto e outubro de 2015 sendo realizadas uma vez por semana nas duas equipes de saúde da USF com duração de 50 minutos, na seguinte estrutura: acolhimento, aplicação do pré-teste, apresentação da proposta do dia, execução da atividade lúdica, espaço para perguntas e dúvidas, e aplicação do pós-teste. Os pré e pó-testes de cada oficina continham as mesmas perguntas, abordando questões sobre comportamentos de risco ou proteção para o desenvolvimento de doenças e alimentação saudável. Os resultados obtidos antes e após as oficinas foram comparados. Nos pré-testes os participantes entendiam como alimentos ricos em gorduras, doces e frituras; e, nos pós-testes, a redução do consumo utilizando alimentos assados ou grelhados, preferir mais FLV e observar o rótulo dos alimentos. Como consequências do consumo excessivo de açúcar afirmaram surgimento de diabetes mellitus, pressão alta, doenças do coração, acrescentando, nos pós-teste, redução da ação da insulina e aumento dos triglicerídeos. Quanto ao consumo diário excessivo de alguns ingredientes, nos prétestes, houve relatos de que o açúcar "engrossa o sangue"; o sal causa hipertensão arterial e inchaço; e o óleo aumenta o colesterol e "entope" a veia. Nos pós-testes obteve-se que o excesso de açúcar pode causar diabetes mellitus, hipertensão arterial e ganho de peso; o sal problemas renais, além das respostas anteriores; e o óleo o mesmo acrescido de aumento do colesterol ruim, triglicérides e peso. No pós-teste relativo obtenção de FLV, sugeriu-se pesquisa de mercado, plantação domiciliar, e indicação de armazenamento refrigerado após higienização para aumentar vida útil do alimento. Como efeitos da prática de atividade física nos pré e pós-testes houve relatos de melhora do humor, resistência física, sono e saúde influenciando no bem-estar, além de propiciar beleza estética, autoconfiança e lazer. No pós-teste relativo obtenção de FLV, sugeriu-se pesquisa de mercado, plantação domiciliar, e indicação de armazenamento refrigerado após higienização para aumentar vida útil do alimento. Como efeitos da prática de atividade física nos pré e pós-testes houve relatos de melhora do humor, resistência física, sono e saúde influenciando no bem-estar. As respostas similares nos dois testes permite concluir que existe compreensão prévia sobre alguns temas, porém outros conhecimentos foram construídos nas intervenções, ou seja, estas estimularam a percepção sobre a importância da alimentação saudável na melhoria da qualidade de vida.
\end{abstract}

Descritores: Educação alimentar e nutricional, Comportamento alimentar, Modelo transteórico 